\title{
University Spirit and the Construction of Learning Atmosphere in Higher Learning Institutions
}

\section{Yin LI}

Wuhan University of Science and Technology

\begin{abstract}
University spirit is the fundamental spirit why university is "universe". It is the ideal of cocreation and co-pursuit which is achieved by long-term efforts of professors in all ages. Construction of learning atmosphere influences the quality of talents cultivated by higher institutions; it is the concentrated reflection and important symbol of university spirit. On the basis of exposition of the relationship between the two, this paper analyses the significance of leading the construction of learning atmosphere by university spirit, and driving the construction of learning atmosphere in higher institutions by university teachers.

KEYWORD: University Spirit; Construction of Learning Atmosphere; University Teachers
\end{abstract}

University is the place where profound knowledge is imparted, the medium of knowledge communication, and the source of developing intelligent. The reason why the university can shine through the ages and be immortalized around the world should owe to her continuous spirit breed in an endless succession. To gain the long-term progress, take the social responsibility, fulfill the destiny endowed by the history, and meet the diverse demands of the society, the modern university should stick to its spirit. The construction of learning atmosphere is the important content of university spirit and the construction of campus culture, meanwhile the important aspects of deepening educational reform and improving the educational quality. Condition of the construction of learning atmosphere directly affects the university teaching order and teaching quality, meanwhile the university's development and social reputation, and together affects the overall development of the students.

University is the place which gathers the intellectual, the palace of studying and spreading scientific knowledge, scientific thought, scientific manner, and scientific spirit. With the increasingly diversity of our country's social economical elements, organizational form, employment form, benefit-based relationship and relation of distribution; University teachers' atmosphere and value orientation of imparting knowledge and educating people present the trend of diversification.
Under the new circumstances of the new age, strengthening the construction of university spirit and the atmosphere, intensifying the university teachers' virtue and teaching style are the fundamental guarantee of fully implement of the party's education policy, are the press for moving forward a single step in strengthening and improving on college students' ideological and political education.

\section{THE RELATIONSHIP BETWEEN THE UNIVERSITY SPIRIT AND THE LEARNING ATMOSPHERE}

\subsection{The implication of university spirit}

University spirit is the essence of university soul. A country has its country spirit, a nation has its national spirit; similarly, a university has its university spirit. A university without unique spirit is like a country without national soul, people with no ambition, and cannot be called "university" in its true sense. University spirit is a kind of abstraction of internal disposition, just as Mr. Xu Baogeng has said: "university spirit is not set artificially, and not the ideal product of the mind of some president or some people. Its formation is the result of the longterm strike and integration of multiple factors. Usually speaking, a university's spirit links together with this university's unique history, geography and

Writer: Li Yin, male, College of Urban Construction of Wuhan University of Science and Technology Director of the office of student work Master Lecturer. Mailing address: College of Urban Construction of Huangiiahu Campus of Wuhan University of Science and Technology. Postcode: 430065. 
cultural circumstances, it is the result of the mutual conflict and integration between the country orientation and the social trends. University spirit's development needs a longer running history, it is the most precious part of university tradition, and is the source of vitality and deposits for the university to fight against strike and seek for development, it plays an important role in stabilizing the university's style and level." Once formed, university spirit will has its distinct traits, coming down in one continuous line, and will highlight distinct time features.

University spirit is the fundamental spirit why university is "universe". In more than one century's history of China's higher education, many universities have formed their unique university spirit. For example, Peking University is famous for "advocating the new, assert free thought, absorb anything and everything"; Tsinghua University is handed down from ancient time for "constantly strive to become stronger, self-discipline and social commitment"; Beijing Normal University is known for "learn to be a teacher, action demonstration". What makes these hundred-year-old universities enduring and young forever is the university spirit which is both common and full of personal charms, it firmly keeps the kingdom of university spirit.

The unique philosophy disposition and cultural atmosphere which the university spirit has bursts with attracting glamour, hence make various researchers endow it with rich implication. The writer of this paper trends to hold the opinion that university spirit is the core element of university culture, it is the high condense of integration of the construction of the spirit culture such as school personality, traits, spirit, ideal, belief, value and so on, in a word, it is the combination of modern sense and university personality, and is widely penetrating into some aspects of group consciousness and spirit power such as the school tradition, learning atmosphere, school atmosphere, target pursuit, moral regulation, leadership style, teaching style, learning style and so on so forth.

\subsection{The implication of learning atmosphere}

Learning atmosphere is a kind of atmosphere, it is a kind of group action, and has potential influence on youthful students whose world outlook is under formation. Excellent learning atmosphere is a positive atmosphere, can make students in it feel stressful so as to have the sense of urgency; at the same time, it is a kind of motivation which can make students aggressive, cheer up, and restrict the breeding and spreading of unhealthy customs.

In the narrow sense, learning atmosphere refers to students' climate for learning, especially students' attitudes towards learning inside and outside the classroom. It is the tendentious and stable attitude and action students show which is specifically reflected in students' learning motivation, attitude, and learning habits. Learning motivation is the internal driving power of students' learning enthusiasm, it can inspire and keep students' study enthusiasm; learning attitude is learning the core part of atmosphere, it can adjust and keep students' learning force, potency dimension and depth during the whole learning process; learning effect is the comprehensive evaluation of stand or fall of learning. Good learning habits of university students mainly reflect on "strict, hard-working, realistic, innovate". Excellent learning atmosphere is to the benefit of students' intellect developing and healthy development of mind and body. With admiring learning atmosphere, youthful students can overcome all kinds of difficulties in study and promote being talents.

In a broad sense, learning atmosphere includes each aspects related with both students' learning and growing up, not only includes students' learning attitudes but also the teaching style, the school culture atmosphere, students' ideology, action behavior and so on. At the same time, it also includes the school's academic atmosphere, the teacher's academic attitude and so on. The connotation of learning atmosphere is a comprehensive reflection of aspects such as school leaders' guidelines for university management, cultivating objectives, learning and work style and so on in the process of setting up the managing idea, teachers' teaching, scholarship and students' learning, including specific learning objectives, strong interest in studying, progressive learning spirit, hard-working learning attitude, favorable learning habits, scientific learning method, strict learning discipline, and time spirit along with the age. In another word, as the essence of university spirit, learning atmosphere refers to a more stable scholarship objective, spirit, attitude, habit and method formed by the university staff and students during the long-term educational practice process, it is a specific reflection of all the staff and students' psychology and action on learning and scholarship.

\subsection{University spirit and its relationship with learning atmosphere.}

Mr Cai Yuanpei thinks: "a university's spirit can be its learning atmosphere, and also can be the style it condenses in a particular situation. Condensation of this kind of style is not unexpected, not even imaginary."

As a overall reflection of a university's presence and educational level, university spirit is the measuring mark of the school staff and students' height of needs, moral sentiment, action, ideal, belief, value, and moral level. As a psychology source, it is intangible. But as a normative power, it 
is specific and sensory. It can externalized as specific school atmosphere, learning atmosphere, playing an important role in the process of the school learning atmosphere construction; it can also be internalized as strong motivation which inspires the school staff and students' forging ahead and untiringly struggle for a common running objective. To be specific, university spirit usually has the function of influence and assimilation, condensation and persuasion, regulation and orientation, together with the function of striving and inspiring. Once formed, the university spirit will have the effect of brainstorming and team spirit on the teacher group, along with the effect of being influenced unconsciously and cultivating one's tastes. And the spirit value this kind of vivid presentation reflects back has better effect of cheering up the mood, inspiring the will, adjusting the mental state and regularize behavior during the process of learning atmosphere construction; namely, from students' learning motivation, learning attitude and learning method to teachers' teaching ideology, attitude and style, then to cadres and staff's behavior attitude, all of them show the trends of positive cycling. What is more important is that as the main culture proclducts and its much important component, university spirit will certainly have an enormous impact on mainstream culture. Therefore, a university will become the guider of school atmosphere, teaching atmosphere, and learning atmosphere, along with the creator of advanced culture if it is equipped with the university spirit.

\section{GUIDING THE CONSTRUCTION OF LEARNING ATMOSPHERE WITH THE UNIVERSITY SPIRIT}

University spirit is a university's soul, is its valuable wealth, is mighty spiritual strength and educating source. Guiding the construction of learning atmosphere and constructing favorable learning atmosphere with the university spirit is the important content of university reform and development, is the fundamental guarantee of improving the quality of cultivating the talents, is the basic revelation of the university's schooling level, is the eternal subject for the university to fully apply the scientific outlook on development, and to realize comprehensive, coordinated and sustainable development.

Mr Mei Sheqi has said: "the so-called scholars are not necessarily large, they are just called masters." "The spirit of a university does not mean the increase of the architecture, but lies in educating the learner...... I think that to educate is not only to instruct the student to read, to study the knowledge. The professor who can lead the student to engage in scholarship can certainly instruct the student to behave, because engaging scholarship is much related with behaving. People who can try hard to engage scholarship honestly will necessarily not cut the corners, be lazy and cheat in conducting themselves, so their scholarship careers have the achievement finally." Therefore, in the construction of learning atmosphere, the key is to stick to the correct schooling idea, adhere to the vigorous scholarship attitude, along with setting up wholesome regulatory framework and service mechanism.

\subsection{Sticking to proper schooling idea is the basis of the construction of the learning atmosphere}

The connotation of the university spirit is very rich, its basis is the divine sense of destiny of cultivating talents for the country; the moral value orientation which both serves the society and leads the society; the scientific spirit of academic freedom and creative and so on. Recently, the educational circle's criticism on "weakness of the university spirit" mainly refers to the "utilitarianism" and "officialdom". The so-called "utilitarianism" is also called "secularization", it means that under the impact of the market economy, the university and the "scholar" put more and more energy on benefits, busy with making money, and people who are real engaged in engaging knowledge is fewer and fewer. The so-called "officialdom" means that the university is more and more like a official circle, everyone fights to get a position, and it is difficult to calm down to engage knowledge. These two situations above is seriously eroding the original divine university, and severely influences the construction of the learning atmosphere of the university.

So the essence of the construction of the university's learning atmosphere is to stick to proper schooling idea. The fundamental reason why the Harvard University can achieve lasting fame is that it sticks to its schooling aim of seeking the truth from the beginning to the end, regarding Harvard as the place imparting knowledge and developing knowledge, and an institution cultivating social leaders and elites, which requires our universities to pay attention all the time: first, set positive value idea, make the teacher combine the realization of its own value with the school's developing objective, establish the sense of competition, fighting, and pulling the sock up, regard contributing the school as highest seek to realize self value. Second, strengthen the construction of teachers' morality. Teachers are masters, and are supposed to possess essential virtues of human beings. Teachers' power of personality is important spirit source of students' development. Therefore, teachers in the new age should have scientific world vie, scientific outlook on life, favorable image of people's teacher to influence and nurture the young generation, together 
with setting a good example for the students. Second, increase cultural awareness. Cultural awareness is revealed in every segment of teachers when imparting and educating people, it influences the teacher's self academic level and innovative practice, and affects the teacher's behavior regulation. Improving teachers' cultural awareness is the important precondition of improving that of the undergraduate, and is necessary support to improve their cultural tastes. Only by sticking to proper schooling idea can we build a university top-ranking internationally, and cultivate qualified constructor and reliable successor for the cause of socialism.

\subsection{Rigorous scholarship attitude is the soul of the construction of learning atmosphere}

The university is the site for the experts to scholarship, it advocates rigorous scholarship so as to form strong academic atmosphere. Rigorous scholarship attitude reveals teachers' strong sense of professionalism and high responsibility, favorable scholarship atmosphere has the effect of directing and demonstrating the learning atmosphere. Teachers' teaching by personal example as well as verbal instruction influences the learning atmosphere intangibly, directly and profoundly. If the instructor himself does not do well, it is easy to have a bad influence on students they instruct, encourage their impetuous mood of seeking quick success and instant benefits, as well as the fluke mind, even leads to the student's degraded conduct in academic. Academic misconduct has now become the "cancer" of the university and the public hazard of the society, and is now slowly spreading and eroding healthy bodies and minds of university staff and students, and needs to be contained firmly.

On the one hand, the university should feasibly strengthen the education of teachers' morality ethics, and improve teachers' accomplishment so as to set a good figure and example for students; on the other hand, the university should fulfill teachers' work norm, strengthen the administration on teachers' teaching process, erect teachers' teaching archives, strictly enforce the teaching discipline, regard imparting knowledge and educating people as major contents to assess the teacher and employment, keep strictly the rules for reward and punishment. Meanwhile, only by imposing severe regulations on education administrators' work style can we effectively strengthen the construction of the scholarship atmosphere, and impel the construction of the learning atmosphere.

\subsection{System construction is the key of the construction of learning atmosphere}

System construction is the basis of reinforcing the administration, administration without education is blind, and education without administration is not complete, we should guide the administration with education, and strengthen the education with administration, request strictly, so strengthening the administration is the guarantee of constructing favorable learning atmosphere.

(1) Fulfill the university reward system, set up inspiring mechanism. Guide the optimum development of scholarship and learning, teaching style and politic style with the guiding role of the inspiring mechanism. Make the education administrator, university teachers and students enthusiastically throw themselves to the construction of the school, academic research, and the innovation of knowledge.

(2) Set up replacement mechanism. Select the superior and eliminate the inferior, keep certain retention rate and prompt teaching benefits teachers as well as students. Build up impartial and reasonable evaluation system. Make the true value of teachers, education administrator, and teachers get approved and revealed through impartial and reasonable evaluation, and form a optimum cycle. Establish positive, rigorous and responsible attitude in competition.

(3) Strengthen students' guidance and education of students on aspects of cultivation objective and specifications, scientific learning method, proper developing path and so on. Quicken the renewal of the classroom teaching content; tightly combine with the requirements of the age ant the society. Carry out some activities such as second classrooms, seminars, system lectures and the like which contain much information, full of technological content, and are of popular interest among students, so as to meet the undergraduates' learning desire, broaden their scopes of knowledge and information quantity. What's more, make students realize their own deficiency and distance through activities, generate the sense of crisis, inspire their initiative studying hard and endeavoring to success, form the learning atmosphere of hard-working, rigorous, and realistic.

(4) Reinforcing the guidance and supervising of teachers' academic atmosphere, teaching style and education administrators' work style. Firmly fight against undesirable academic atmosphere and teaching style, fulfill the university's administrative supervision system, and strictly specify rights and obligation of education administrators and teachers.

\subsection{Improving the service system is the guarantee of the construction of learning atmosphere}

Set up complete service system; improve the awareness and quality of serving the teacher and the student, make the subject of the construction of learning atmosphere put main energy on seeking and practice of the objective ideal, so as to provide 
logistical support for the construction of the learning atmosphere.

(1) Leading cadres of all levels of the university should firmly establish the awareness of "leading is service", improve the consciousness of being a good "director for logistics". They should care for basic necessities of life of the university staff and students, starts from side minor matter, stand out humanistic care, accomplish every piece of work of serving the teacher and the student.

(2) Emphasize the work of both teachers and students, the construction of the learning environment. Focus on the forestation and beautification of the school environment, build strong academic atmosphere. At the same time, the library, the laboratory and the computer centre, the logistic guarantee system should provide convenient and fast service; solve teachers and students' worries.

(3) Attach importance to teachers' education of healthy psychology. The reform and development of education, the change of the market economy system, and the public's needs for superior education make the broad masses of teachers face great stress. Therefore, university leaders should thinner ideological work, create fair, impartial, democratic, united and mild work environment, build up forceful guarantee for the construction of learning atmosphere.

\section{REFERENCES}

[1] Higher Education Department of Education Ministry. Meeting of the University Teaching Work Directly under the Education Ministry. An Hui People's Publishing House, 2001

[2] Liu Huashan. Introduction to University Educational Psychology. Central China Normal University Press, 1991-3

[3] Xing Shaoying. Psychological Problems and Adjustment of University Teachers in the New Age. China Higher Education Research, 2002-6

[4] Chang Yanfang. Timing Representation of University Spirit. Journal of Northeast Normal University(philosophical and social science edition), 2004-3

[5] Han Yanming. Construction of the Learning Atmosphere: Eternal Subject of University's Sustainable Development. Higher Education Research. 2006-3

[6] Wang Xianping. Reflection and Countermeasure on Construction of University's Learning Atmosphere. Journal of Nanyang Normal University(social science edition), 2006-7 